\title{
Modelagem computacional de reservatório de detenção sob logradouro: uma alternativa para controle de alagamentos em área densamente urbanizada do Recife/PE
}

\section{Computational modeling of detention reservoir under street: an alternative for flooding control in densely urbanized area of Recife/PE}

Data de entrada: 10/10/2018

Data de aprovação: 05/07/2019

Simone Rosa da Silva ${ }^{1 *}$ | Marcos Antonio Barbosa da Silva Junior² | Regina Lúcia Melo de Oliveira1 DOI: https://doi.org/10.36659/dae.2020.075

ORCID ID

Silva SR (iD https://orcid.org/0000-0001-7138-7546
Silva Junior MAB (D) https://orcid.org/0000-0002-2678-9420 Oliveira RLM (D) https://orcid.org/0000-0002-0859-0549

\section{Resumo}

Este artigo avalia, por meio de modelagem computacional, a implantação de um reservatório de detenção sob logradouro para controle dos alagamentos em área de urbanização consolidada do Recife/PE. Para isso, foram obtidos os dados físicos da área (cadastro da microdrenagem; percentual de impermeabilização do solo; taxa de infiltração; chuva de projeto; e curva de maré), integrando-os ao modelo SWMM (Storm Water Management Model). $O$ reservatório foi dimensionado pelo método das chuvas e ajustado às condições locais, resultando em um volume de $740 \mathrm{~m}^{3}$. Os resultados mostraram que houve redução dos picos de cheia, em $63,85 \%$, e consequentemente a diminuição da área de alagamento. A capacidade percentual de acumulação do reservatório proposto foi de $45 \%$, quando simulados os eventos de chuva de dois anos de recorrência. Apesar do desempenho satisfatório, o custo de implantação do reservatório é elevado e ele necessita de manutenção sistêmica.

Palavras-chave: Urbanização. Alagamentos. Modelo Hidráulico-Hidrológico (SWMM). Reservatório de Detenção. Logradouros.

\section{Abstract}

This article evaluates, through computational modeling, the implementation of a reservoir of detention under street for flooding control in consolidated urbanization area of Recife/PE. For this purpose, the physical data of the area (microdrainage register, percentage of waterproofing of the soil, in filtration rate, project rainfall project, and tide curve) were obtained by integrating them with the SWMM (Storm Water Management Model) model. The reservoir was dimensioned by the rainfall method and adjusted to local conditions, resulting in a volume of $740 \mathrm{~m}^{3}$. The results showed that there was a reduction of the flood peaks, in $63.85 \%$, and consequently the reduction of flood area. The percentage capacity of accumulation of the proposed reservoir was $45 \%$, when simulated rainfall events of two years of recurrence. Despite satisfactory performance, the cost of reservoir implantation is high, and it requires systemic maintenance.

Keywords: Urbanization. Floods. Hydraulic-Hydrological Model (SWMM). Detention Reservoir. Streets.

\footnotetext{
1 Universidade de Pernambuco - Recife - Pernambuco - Brasil.

${ }^{2}$ Universidade Federal de Pernambuco - Recife - Pernambuco - Brasil.

* Autora correspondente: simonerosaapoli.br.
} 


\section{INTRODUÇÃO}

Nas últimas décadas, os municípios brasileiros apresentaram um processo acelerado e não planejado de urbanização. O desenvolvimento deste processo produziu grandes alterações no ambiente urbano, que se projetaram em impactos significativos sobre a drenagem das águas pluviais. Com o aumento das áreas impermeabilizadas, há uma diminuição do escoamento subterrâneo e subsuperficial, e um consequente aumento do escoamento superficial. 0 reflexo negativo desse aumento é o sobrecarregamento da infraestrutura de drenagem existente, principalmente nos pontos mais frágeis do sistema, resultando em pontos críticos de alagamento durante os períodos chuvosos (SILVA JUNIOR; SILVA, 2016; SILVA JUNIOR, 2015).

Tucci (2000) afirma que a impermeabilização de $7 \%$ da área dos lotes já acarreta a duplicação do escoamento superficial. Nos casos mais extremos, considerando uma impermeabilização de $80 \%$ da área do lote, é possível que o escoamento superficial seja oito vezes maior.

Essa situação se agrava principalmente nas planícies costeiras, como é o caso da cidade do Recife, que teve seu processo de ocupação urbana de forma desordenada e possui um sistema de drenagem altamente vulnerável às oscilações de maré, podendo provocar sérios problemas de alagamentos em períodos de chuvas intensas combinados com eventos de maré de sizígia. No início da formação da cidade, o coeficiente de escoamento superficial (runoff) era da ordem de 0,15 , ou seja, $15 \%$ da água precipitada escoava superficialmente. Atualmente, com o município fortemente urbanizado, o runoff em algumas áreas pode superar 0,80. Com esse cenário, foram identificados pela Empresa de Manutenção e Limpeza Urbana - EMLURB, 159 pontos de alagamentos em toda a cidade (Silva Junior \& Silva, 2016; EMLURB, 2016).
O planejamento da rede de drenagem integrado com o desenho urbano é o primeiro passo para reduzir os problemas relacionados aos alagamentos urbanos. Como na maioria das cidades brasileiras não há esse tipo de planejamento, o que ocorre, muitas vezes, é a adoção de medidas estruturais que contornem essa falha. Por muito tempo, a política higienista que norteava as soluções da drenagem urbana, baseada na canalização dos escoamentos, apenas transferindo para jusante as inundações, fez com que a população arcasse com duas consequências: custo de sistema clássico de drenagem mais alto e maiores inundações (SILVA JUNIOR et al., 2017b).

Atualmente, a tendência moderna na área de drenagem urbana é a utilização de dispositivos ou medidas de controle dos escoamentos, evitando, assim, os alagamentos nos centros urbanos. Essas medidas, conhecidas como técnicas alternativas/ compensatórias de drenagem, buscam controlar os escoamentos por meio da recuperação da capacidade de infiltração ou da detenção do escoamento adicional gerada pela superfície urbana. Baptista et al. (2011) definem essas técnicas como dispositivos que buscam neutralizar os efeitos da impermeabilização do solo sobre os processos hidrológicos, com benefícios para a qualidade de vida e a preservação ambiental.

Para implementação das medidas citadas é necessário, primeiramente, avaliar o efeito das possíveis modificações a serem realizadas e as soluções mais eficientes para cada situação, empregando na maioria dos casos modelos hidrológicos/hidráulicos para as condições atuais e futuras da bacia. Existem diversos modelos hidrológicos para várias finalidades. Os modelos hidrológicos disponíveis com o objetivo de determinar vazões de cheia em bacias hidrográficas são denominados de chuva-vazão e, como exemplos, têm-se: o Model for Urban Sewers (MOUSE), o Hydrological Model System (HEC-HMS) e o Storm 
Water Management Model (SWMM) (LIONG \& YBRAHIM, 1994; FORMIGA et al., 2016).

Diante da necessidade de mitigar os impactos dos alagamentos urbanos no Recife, recentemente vêm-se estudando técnicas compensatórias de drenagem que melhor se adequam ao desenho urbano atual da cidade. É nessa realidade que os reservatórios de detenção em logradouros têm-se mostrado uma técnica possível de ser implantada, apresentando também resultados satisfatórios de redução dos picos de vazões e da sobrecarga do sistema de microdrenagem. Estudos recentes em pontos críticos de alagamentos da cidade foram desenvolvidos por Cabral et al. (2009), Silva \& Cabral (2014), Silva Junior et al. (2017a) e Oliveira (2017), em que se verificou o desempenho hidráulico da citada técnica junto com a diminuição dos níveis de alagamentos, a partir de simulações hidráulico-hidrológicas.

Em 2007, o reservatório de detenção proposto por Cabral et al. (2009) foi efetivamente construído no bairro do Espinheiro, zona norte do Recife, entre as ruas Conselheiro Portela e Santo Elias, com um volume de armazenamento de $200 \mathrm{~m}^{3}$. A estrutura de drenagem custou à prefeitura da cidade um investimento de $\mathrm{R} \$ 336.446,54$ e diminuiu significativamente a incidência de alagamentos na área, que antes chegava a uma altura de 50 centímetros. Com a implantação da citada obra, os prejuízos financeiros para os comerciantes locais, bem como os transtornos para mobilidade urbana na área foram reduzidos em dias de chuva (MELO et al., 2013; SILVA JUNIOR et al., 2017b).

Dentro desse contexto, o presente estudo avalia, por meio de modelagem computacional, a proposta de implantação de um reservatório de detenção on-line a rede de drenagem, locado em logradouro, para reduzir o impacto hidrológico da impermeabilização do solo em área do Recife-PE. Em complemento, é apresentado um estudo de viabilidade financeira para a construção da citada estrutura de drenagem.

\section{METODOLOGIA}

\section{1 Área de Estudo}

$O$ ponto de alagamento encontra-se localizado na bacia do rio Jiquiá (principal afluente do rio Tejipió), situado no bairro do Jiquiá, mais especificamente no cruzamento entre a Avenida Doutor José Rufino e a Rua João Teixeira (Fig. 1).

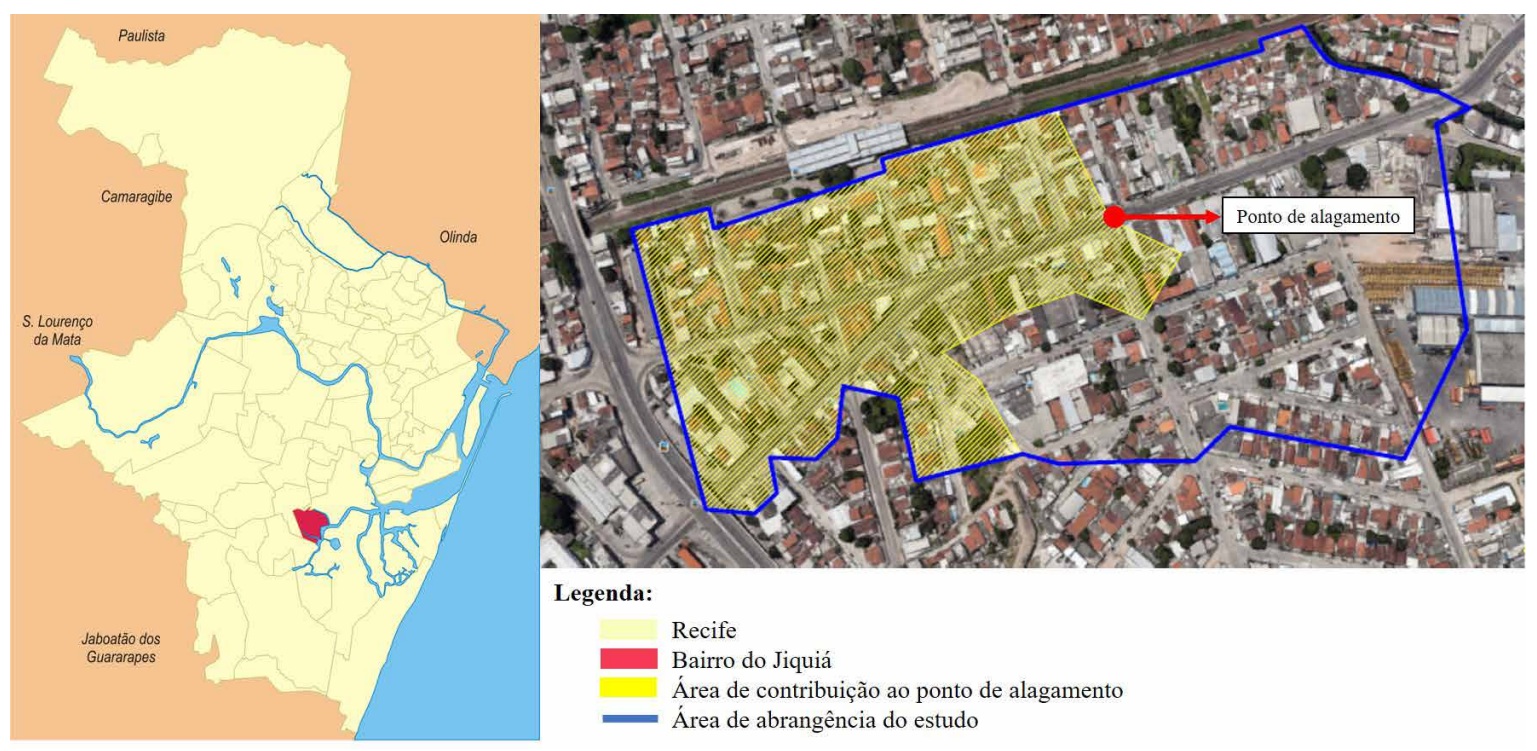

Figura 1 - Localização e delimitação da área de estudo. 
A área de estudo apresenta 16,36ha e foi definida pela extensão do sistema de microdrenagem local até o seu exutório, no rio Jiquiá.

A área de contribuição ao ponto de alagamento, que segundo a Lei Municipal No 16.176 de Uso e Ocupação do Solo da Cidade do Recife (Recife, 1996) possibilita alto poder construtivo (adensamento/ocupação), possui uma taxa de impermeabilização do solo superior a $90 \%$ e é predominantemente residencial, com concentração de estabelecimentos comerciais e escolas. Possui uma área aproximada de 7,6ha.
Os dados censitários do IBGE mostraram que a população residencial do bairro do Jiquiá aumentou $31 \%$ entre os anos de 2000 e 2010 (IBGE, 2000, 2010). Tucci (2000) afirma que um habitante introduz cerca de $49 \mathrm{~m}^{2}$ de área impermeável na bacia e para cada $10 \%$ de área impermeável, ocorre cerca de $100 \%$ de aumento no coeficiente de escoamento de cheia e no volume de escoamento superficial. Assim, esse crescimento acelerado tem comprometido a infraestrutura de drenagem, que não acompanha o processo de urbanização, refletindo na sobrecarga das tubulações existentes e ocasionando os alagamentos (Fig.2).
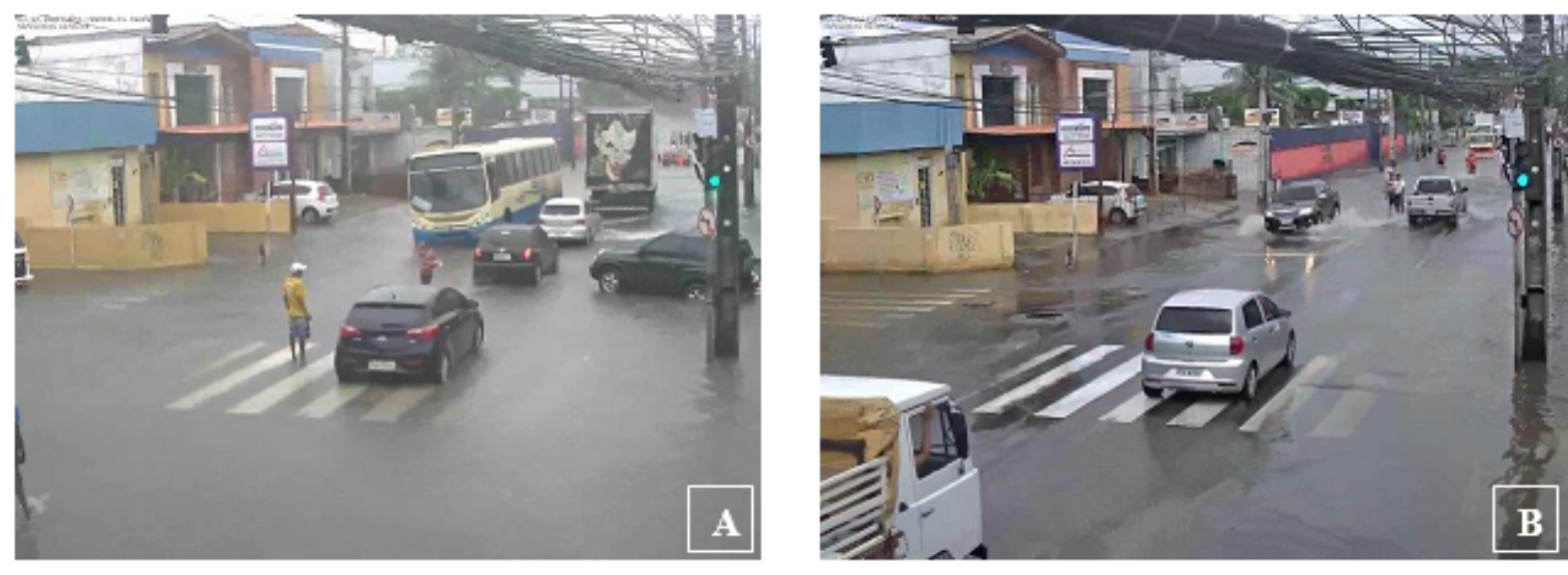

Figura 2 - Alagamento na Avenida Doutor José Rufino em 09 de maio de 2016 (a) e em 30 de maio de 2016 (b). Fonte: CTTU (2016).

\subsection{Modelo Hidráulico-Hidrológico}

Para a modelagem hidráulica-hidrológica foi utilizado o software SWMM (Storm Water Management Model), desenvolvido pela United States Environmental Protection Agency (US EPA) em 1971, na sua versão mais recente, a 5.00.22. Consiste num modelo dinâmico "chuva-vazão", com código fonte aberto e que tem sido amplamente utilizado por diversos pesquisadores, auxiliando no planejamento e no desenvolvimento de projetos relacionados ao escoamento de águas pluviais e esgotos sanitários.

O funcionamento computacional do modelo é dividido em quatro módulos de simulação: Runoff, que compreende a transformação chuva-vazão e gera o escoamento superficial; Transport, que é responsável pela propagação do escoamento através da rede de drenagem pelo método da onda cinemática; Extran, que realiza a simulação hidráulica em condutos e canais por meio do método hidrodinâmico; e Storage/Treatment, que é responsável pela simulação de processos de tratamento e armazenamento, visando à qualidade da água. Na modelagem realizada, foram utilizados apenas os três primeiros módulos.

No ambiente do modelo, o sistema de drenagem é representado por junções/nós (poços de visita) e condutos (galerias e tubulações), atribuindo-lhes 
cotas topográficas e extensões dos elementos de drenagem, com base no cadastro da rede. As subbacias são caracterizadas pelos parâmetros físicos de entrada do modelo, como: área (ha); largura (m); declividade (\%); áreas impermeáveis (\%); coeficiente de rugosidade de Manning ( $\mathrm{s} / \mathrm{m} 1 / 3$ ) para as áreas permeáveis e impermeáveis; e profundidade de armazenamento em depressões $(\mathrm{mm})$ para as áreas permeáveis e impermeáveis. As variáveis de entrada compreendem as séries de dados de precipitação e maré, e taxas de infiltração.

\subsubsection{Parâmetros Físicos e Séries Variáveis de Entrada}

\section{a) Parâmetros:}

1) Cadastro da rede de drenagem: $O$ cadastro do sistema de microdrenagem de águas pluviais da área em estudo foi cedido, em ambiente CAD, pela Secretaria de Infraestrutura e Serviços Urbanos - Empresa de Manutenção e Limpeza Urbana (EMLURB), da prefeitura do Recife. Foram coletadas informações dos poços de visita (localização, profundidade, cotas da tampa e do radier) e das galerias (comprimento, declividade, geometria do conduto).

2) Sub-bacias: Com a definição da área da abrangência do estudo, foram feitas as subdivisões de cada área de contribuição a cada poço de visita considerado no modelo, resultando num total de 12 sub-bacias. Esse processo foi realizado no ambiente CAD, com base na delimitação dos lotes e quadras (dados da UNIBASE do Recife), na topografia da área (curvas de nível de $1 \mathrm{~m}$ disponível no site de Informações Geográficas do Recife - ESIG) e nos subsistemas de microdrenagem existentes (cadastro de drenagem da EMLURB). Após esse processo, foram obtidas as seguintes características físicas:
- Área e largura das sub-bacias: A área foi obtida em CAD, após o processo de delimitação das sub-bacias descrito anteriormente. A largura foi obtida pelo método do retângulo equivalente (Eq. 1), em função da largura equivalente - Le (Eq. 2) e do coeficiente de compacidade - Kc (Eq. 3).

$$
\begin{aligned}
& W=\frac{A}{L e} \\
& L e=0,893 \times(K c \times \sqrt{A}) \times\left[1-\sqrt{1-\left(\frac{1,128}{K c}\right)^{2}}\right] \\
& K c=0,282 \times\left(\frac{P}{\sqrt{A}}\right)
\end{aligned}
$$

Onde: W - largura da sub-bacia (m); A - área da sub-bacia $\left(\mathrm{m}^{2}\right)$; Le - largura equivalente $(\mathrm{m}) ; \mathrm{P}$ perímetro da sub-bacia $(\mathrm{m}) ; \mathrm{Kc}$ - coeficiente de compacidade.

- Declividade: As declividades superficiais de cada sub-bacia foram obtidas por meio do nivelamento topográfico dos topos dos poços de visita existentes, com base no cadastro de microdrenagem cedido pela EMLURB.

- Taxa de impermeabilização: O cadastramento de áreas verdes, ruas não pavimentadas e lotes com solo exposto foi realizado em ambiente CAD, utilizando as ortofotos da cidade do Recife, do ano de 2013, disponibilizadas no site do ESIG - Informações Geográficas do Recife. A validação desse cadastramento foi feita com imagens mais recentes do Google Earth e visitas ao local. Com a aplicação desses recursos, foi possível observar que a maioria das sub-bacias possui sua superfície $100 \%$ impermeabilizada.

- Coeficiente de rugosidade de Manning e profundidade de armazenamento em depressões: os valores utilizados, inicialmente, foram sugeridos por Canholi (2015), Silva \& Cabral (2014) e Silva Junior et al. (2017a) - Coeficiente de rugosidade de Manning (Áreas Permeáveis: 0,15s/m1/3/ 
Áreas Impermeáveis: 0,024s/m1/3) e altura de armazenamento em depressões (Áreas Permeáveis: 0,20pol - 5mm/Áreas Impermeáveis: 0,10pol - 2,54mm). É importante salientar que, na etapa de calibração do modelo, tais valores foram alterados até que se representassem, para os eventos simulados, a extensão e a profundidade dos alagamentos observados no local.

\section{b) Variáveis:}

1) Chuva de projeto: foram utilizados os dados horários de precipitação da estação Areias 261160621A, operada pelo CEMADEN (Centro Nacional de Monitoramento e Alerta de Desastres Naturais), localizada num raio aproximado de $4 \mathrm{~km}$ de distância da área estudada. Para as simulações hidrológicas, considerou-se o evento chuvoso ocorrido no dia 09 de maio de 2016, com duração de 23 horas e um total precipitado de $121,8 \mathrm{~mm}$. Também foi considerado o evento chuvoso que ocorreu em 30 de maio de 2016, com duração de 14 horas e um total precipitado de $112,80 \mathrm{~mm}$.

2) Curva de maré: essa variável foi utilizada como condição de contorno no exutório do sistema. Tomando por base os eventos de chuva considerados, foram obtidos os oito registros de alturas de maré ( 4 preamares e 4 baixa-mares) na tábua de maré do Porto do Recife, disponibilizado no site da Diretoria de Hidrografia e Navegação - DHN (DHN, 2016). Com esses dados, a curva foi obtida a partir da interpolação das alturas de marés para o intervalo de tempo de 1 hora, considerando as durações dos eventos de chuva simulados. Os valores obtidos foram convertidos para o Sistema de Referência de Nível da Cidade do Recife, que está nivelado ao zero Hidrográfico do Porto do Recife, de acordo com o Departamento Nacional de Portos e Viação Náutica - DNPVN.

3) Taxa de infiltração: o SWMM considera três modelos diferentes para a determinação da variável infiltração da chuva em zona não saturada do solo nas áreas permeáveis (modelo de infiltração de Horton, Green-Ampt e Curva Número do SCS). Dentre estes, optou-se pelo modelo de Horton (Eq. 4 e 5), e os termos da equação foram obtidos a partir dos testes de infiltração realizados pela EMLURB (EMLURB, 2016) numa área próxima da Avenida Doutor José Rufino, resultando na Eq. 6 a seguir:

$$
\begin{aligned}
& I_{t}=I_{b}+\left(I_{o}-I_{b}\right) \exp (-k \times t) \\
& k=\frac{\left(I_{o}-I_{b}\right)}{F C}
\end{aligned}
$$

Onde: $I_{t}$ - taxa de infiltração no tempo $(\mathrm{mm} / \mathrm{h}) ; \mathrm{I}_{\mathrm{b}}$ taxa de infiltração final $(\mathrm{mm} / \mathrm{h}) ; \mathrm{I}_{\mathrm{o}}$ - taxa de infiltração inicial (mm/h); t - tempo (h); k - constante de decaimento $\left(\mathrm{s}^{-1}\right) ; \mathrm{F}_{\mathrm{c}}$ - área sob a curva de infiltração.

$I_{t}=273,81+217,188 e^{-1,788 t}$

Com base na equação da curva de infiltração apresentada (Eq. 6), ajustada à equação de Horton, foi possível a obtenção dos parâmetros para a inserção no modelo: as taxas máxima e mínima de infiltração $(273,81 \mathrm{~mm} / \mathrm{h}$ e $217,188 \mathrm{~mm} / \mathrm{h}$, respectivamente), e a constante de decaimento $(1,788)$.

\subsubsection{Montagem da Rede de Drenagem no Modelo}

Na Fig. 3 é apresentado o layout do modelo, com base nas informações descritas anteriormente, mostrando a rede de drenagem implantada no SWMM. Entre as seções transversais dos condutos disponíveis no programa, optou-se pelas tubulações de concreto, circulares e com preenchimento, devido ao acúmulo de sedimentos depositados no fundo das galerias. $O$ coeficiente de rugosidade de Manning adotado foi de $0,011 \mathrm{~s} / \mathrm{m}^{1 / 3}$, característico de condutos fechados de concreto. 


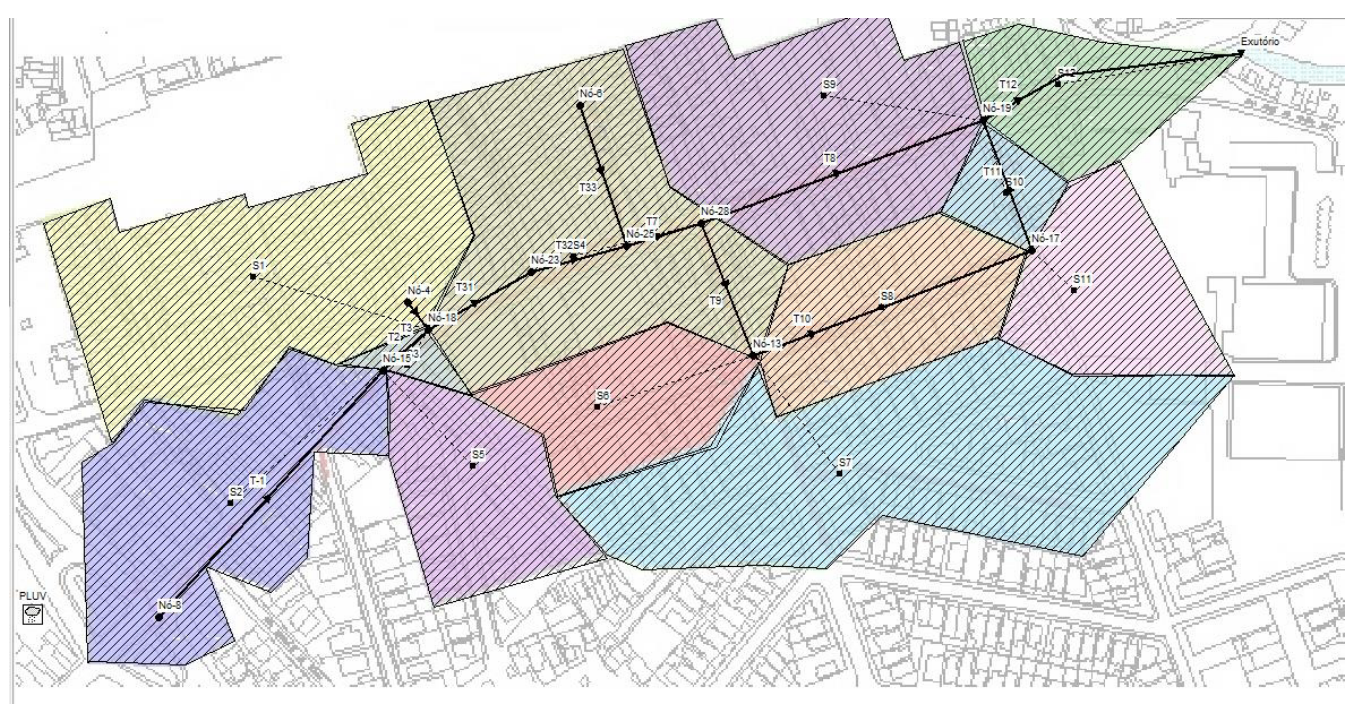

Figura 3 - Rede de drenagem implantada no modelo SWMM.

\subsubsection{Calibração e Validação do Modelo}

Na ausência de sensores de nível ou de medidores de vazão na área estudada, necessários para processar um estudo de sensibilidade, calibração e validação dos parâmetros, optou-se por realizar uma calibração simplificada do modelo, baseada somente no ajuste do volume de inundação simulado ao observado durante a ocorrência do evento de 09 de maio de 2016, apenas no ponto de controle. Esse mesmo procedimento também já foi adotado por outros autores, como Silva \& Cabral (2014) e Silva Junior et al. (2017a).

Procedendo dessa forma, a calibração obtida pode ser definida como um processo expedito, uma vez que a mesma foi realizada de forma manual, por meio da manipulação de dois parâmetros: coeficiente de rugosidade de Manning e profundidade de armazenamento em depressões, ambos para as áreas permeáveis e impermeáveis de cada sub-bacia. Os valores atribuídos a tais parâmetros variaram dentro dos intervalos apresentados na Tabela 1, sugeridos no manual do usuário do SWMM (Eletrobrás/PROCEL-SANEAR, 2012).
Tabela 1 - Intervalos de coeficientes adotados no modelo.

\begin{tabular}{|c|c|c|c|}
\hline \multicolumn{2}{|c|}{ Parâmetro } & Mínimo & Máximo \\
\hline $\begin{array}{c}\text { Coeficiente de } \\
\text { rugosidade de Manning } \\
\left(\mathrm{s} / \mathrm{m}^{1 / 3}\right)\end{array}$ & Área permeável & 0,010 & 0,040 \\
\cline { 2 - 4 } & Área impermeável & 0,100 & 0,800 \\
\hline $\begin{array}{c}\text { Prof. de armazenamento } \\
\text { em depressões }(\mathrm{mm})\end{array}$ & Área permeável & 1,27 & 2,54 \\
\cline { 2 - 4 } & Área impermeável & 2,54 & 7,62 \\
\hline
\end{tabular}

Fonte: Eletrobrás/PROCEL-SANEAR (2012)

De uma maneira geral, o objetivo desse processo foi representar a condição atual do sistema, considerando a inundação no cruzamento entre a Avenida Doutor José Rufino e a Rua João Teixeira (ponto de controle), manipulando-se os parâmetros citados anteriormente, a fim de que o volume máximo de alagamento simulado no sobredito cruzamento estivesse compatível com a vistoria procedida no local durante o evento de chuva considerado.

Para validar os valores de vazão afluentes ao ponto de controle, realizou-se uma nova simulação considerando o evento chuvoso de 30 de maio de 2016, que apresentou características semelhantes ao evento de precipitação utilizado na calibração. Em complemento, foi realizada uma ve- 
rificação desses resultados, comparando-os com os valores de vazão obtidos pelo Método Racional (Eq. 7), que é bastante utilizado nos projetos de bacias pequenas $\leq 2 \mathrm{~km}^{2}$ (Tucci, 2015), como é o caso da área de contribuição ao ponto de controle.

$$
Q=0,00278 \times C \times i \times A
$$

Onde: Q - vazão $\left(\mathrm{m}^{3} / \mathrm{s}\right)$; C - coeficiente de escoamento; $\mathrm{i}$ - intensidade da precipitação de projeto (mm/h), A - área da bacia contribuinte (ha).

\subsection{Dimensionamento do Reservatório}

O critério normalmente utilizado para o dimensionamento dos reservatórios é não permitir que a vazão máxima da área, que passou pelo processo de desenvolvimento, supere a vazão máxima nas condições pré-existentes, para um tempo de retorno escolhido.

Existem diferentes métodos para a estimativa do volume de detenção, muitos dos quais são denominados de simplificados. A experiência tem mostrado que os métodos baseados na utilização de modelos hidrodinâmicos (SWMM, HEC-RAS, etc.) compensam o esforço adicional na etapa de dimensionamento, visto que permitem uma economia dos custos e a detecção de falhas de dimensionamento hidráulico no projeto, impossíveis de serem visadas com as metodologias mais simplificadas (Neves et al., 2005).

Com a utilização do SWMM, visando simular a eficiência da solução proposta para o dimensionamento preliminar do reservatório de detenção, foram aplicados métodos que definem o volume de armazenamento e também a vazão pelo Método Racional e equação da continuidade (Q⿱宀) ).

Dentre os métodos existentes para obtenção do volume de armazenamento, optou-se pela aplicação do método das chuvas (Eq. 8), definido por
Baptista et al. (2011), devido à reduzida quantidade de parâmetros de entrada para a adoção de tal método, necessitando basicamente, das curvas IDF/PDF relativas a longos períodos.

$$
D H \text { má } x=\text { Máx }\left[P(D, T)-q_{s} \times D\right]
$$

Onde: DHmáx - altura máxima a armazenar (m); $P(D, T)$ - precipitação máxima $(\mathrm{mm})$; qs - vazão específica ( $\mathrm{mm} / \mathrm{min}) ; \mathrm{D}$ - duração da precipitação (min ou h).

$q_{s}=\frac{Q_{s}}{A_{a}}$

Onde: $q_{s}$ - vazão específica ( $\left.\mathrm{mm} / \mathrm{min}\right) ; \mathrm{Q}_{\mathrm{s}}$ - vazão de saída $\left(\mathrm{m}^{3} / \mathrm{s}\right) ; A_{a}$ - área de drenagem efetiva $\left(\mathrm{m}^{2}\right)$; $\mathrm{Aa}$ - A (área da bacia em $\mathrm{m}^{2}$ ) $\times \mathrm{C}$ (coeficiente de escoamento pós-urbanização).

Logo, o volume máximo de armazenamento será dado pela Eq. 10:

Vmáx $=$ DHmá $\times A_{a}$

Onde: $\mathrm{V}_{\text {máx }}$ - volume máximo $\left(\mathrm{m}^{3}\right)$.

Neste trabalho, optou-se pelo dimensionamento de um reservatório de detenção on-line, ou seja, encontra-se locado ao longo da rede de drenagem principal e restitui o escoamento de forma atenuada e retardada ao sistema de drenagem, de maneira contínua, normalmente por gravidade.

Após a definição do volume de armazenamento, o reservatório foi projetado e implantado no SWMM, onde foram simuladas novas hidrógrafas para avaliar a redução das vazões de pico e do volume de alagamento, durante os eventos considerados.

Por fim, foi realizada uma estimativa de custo inerente à construção da sobredita estrutura, considerando o levantamento de quantitativos 
do projeto básico do reservatório e a tabela de preços mais recente da EMLURB (EMLURB, 2018), que é o órgão gestor da drenagem urbana do Recife, com data base: julho/2018.

\section{RESULTADOS E DISCUSSÃO}

\subsection{Análise dos Eventos Simulados}

Conforme já mencionado, foram simulados dois eventos extremos de precipitação, ambos registrados no mês de maio de 2016. Juntos, os dois eventos ocorridos nos dias 09 e 30 totalizaram uma altura pluviométrica de $234,60 \mathrm{~mm}$, representando $71,33 \%$ do total precipitado no sobredito mês. Para ambos os eventos considerados, a recorrência calculada foi de 2 anos, com base na nova equação IDF do Recife, desenvolvida no âmbito do Plano Diretor de Drenagem Urbana do Recife (EMLURB, 2016).

A Fig. 4 mostra a distribuição pluviométrica dos eventos simulados e a representação da curva de maré. Observa-se que, no evento do dia 09, o período de maior precipitação, que se concentrou entre 14 e $16 \mathrm{~h}$, ocorreu pouco tempo antes de a maré atingir seu pico de $2,3 \mathrm{~m}$, registrado às $18 \mathrm{~h} 06$. É válido destacar que, nos dois dias que antecederam o evento, foi registrado apenas $1,6 \mathrm{~mm}$ de chuva, o que garante que o sistema de drenagem não estaria sobrecarregado no momento da ocorrência do evento. Mesmo assim, a chuva do dia 09 ocasionou alagamentos significativos não só no ponto crítico estudado, mas também em vários pontos da cidade do Recife, prejudicando seriamente o tráfego de veículos e causando prejuízos econômicos.

Esse problema voltou a se repetir no dia 30 e causou transtornos similares aos observados no evento do dia 09. Também se observaram altos índices de precipitação nas horas que antecederam o pico da maré, às $10 \mathrm{~h} 45$. Nos dois dias que antecederam a ocorrência desse evento, foram registrados apenas $3,6 \mathrm{~mm}$ de precipitação.

Em termos de total precipitado, verifica-se a similaridade entre os eventos simulados (evento do dia $09=121,80 \mathrm{~mm}$ e evento do dia $30=112,80 \mathrm{~mm}$ ), porém encontram-se distribuídos numa escala temporal diferente (evento do dia $09=23 \mathrm{~h}$ e evento do dia $30=14 \mathrm{~h}$ ). Quando analisada a maré, o evento do dia 09 apresentou amplitude de 2,4m, caracterizando uma maré de sizígia. Já no evento do dia 30, a amplitude de maré registrada foi de $1,4 \mathrm{~m}$, caracterizando uma maré de quadratura.

De maneira geral, durante a ocorrência dos eventos considerados, observou-se na área de estudo que a lâmina d'água máxima de alagamento, obtida em campo e com moradores locais, chegou a $17 \mathrm{~cm}$. Na oportunidade também se definiu uma planície de alagamento, com o auxílio do AutoCAD 2015, que correspondeu a uma área aproximada de $2908,00 \mathrm{~m}^{2}$ e um volume de alagamento aproximado de $494,36 \mathrm{~m}^{3}$.
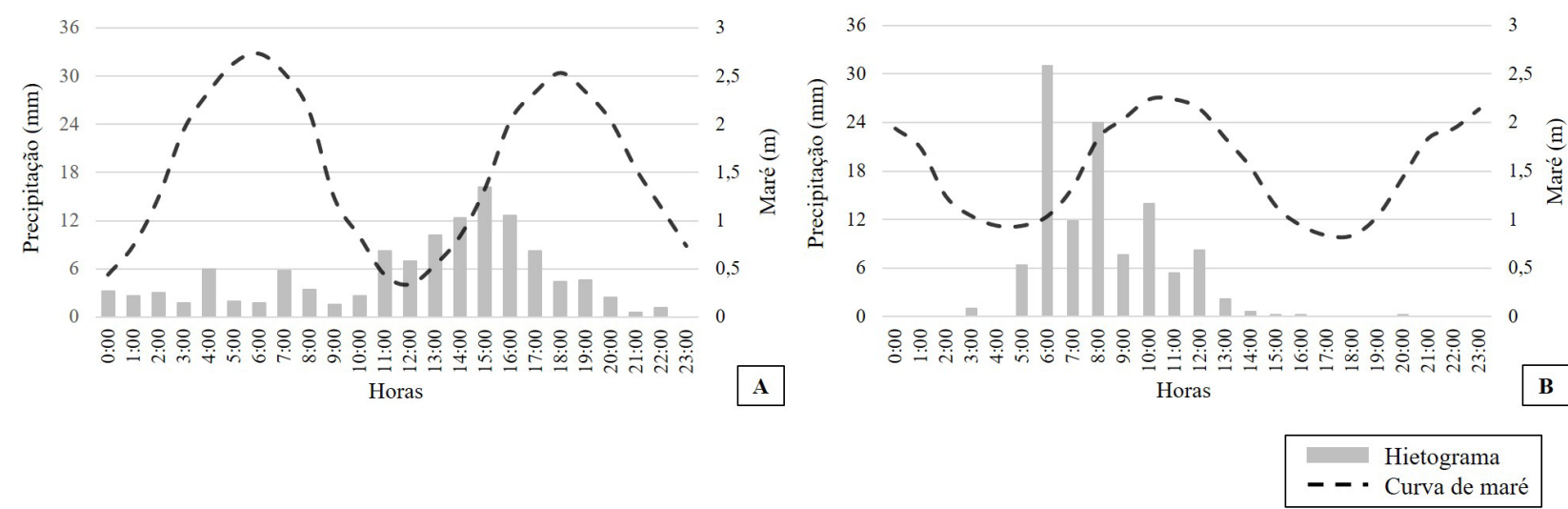

Figura 4 - Gráfico relacionando precipitação e maré em 09 de maio de 2016 (a) e em 30 de maio de 2016 (b). 


\subsection{Simulação da Condição Atual}

A calibração simplificada do modelo buscou representar a condição atual dos alagamentos ocorridos na Avenida Doutor José Rufino. As lâminas e os volumes de alagamentos simulados no ponto de controle, representado pelo poço de visita Nó-28 no SWMM, foram ajustados aos valores medidos em campo. Com os ajustes realizados, verificou-se que a simulação do evento de 09 de maio de 2016 apresentou resultados de lâmina e volume de alagamentos bem próximos aos valores observados, com erros médios de continuidade para o escoamento superficial de $-0,08 \%$ e propagação de vazão $-4,01 \%$ (Tabela 2).

O balanço hídrico da área mostrou que, dos $121,80 \mathrm{~mm}$ precipitados no dia 09 , apenas $2,12 \mathrm{~mm}$ se infiltraram, representando aproximadamente $2 \%$ do total precipitado, enquanto $98 \%$ se converteram em escoamento superficial. Esse dado condiz com a alta taxa de impermeabilização do solo presente na área estudada.
Tabela 2 - Principais resultados obtidos na simulação da condição atual.

\begin{tabular}{|c|c|c|c|}
\hline \multicolumn{2}{|c|}{ Aspectos } & Observado & Simulado \\
\hline \multicolumn{2}{|c|}{$\begin{array}{c}\text { Lâmina d'água máxima } \\
\text { de alagamento }\end{array}$} & 0,17 & 0,15 \\
\hline \multicolumn{2}{|c|}{ Volume máximo de inundação } & 494,36 & 436,20 \\
\hline \multirow{2}{*}{ Erros } & Escoamento superficial & 1,27 & 2,54 \\
\cline { 2 - 4 } & Propagação de vazão & 2,54 & 7,62 \\
\hline
\end{tabular}

No que se refere aos erros de continuidade encontrados durante o processo de simulação (definido pela diferença, em porcentagem, entre a quantidade armazenada inicialmente mais o fluxo que entra e a quantidade armazenada no final mais o fluxo que sai), os mesmos se encontram dentro do limite da aceitabilidade, apresentando valores menores que 10\% (Eletrobrás/PROCEL-SANEAR, 2012).

Nessas condições, a Fig. 5 apresenta as hidrógrafas simuladas e afluentes ao ponto de controle (Nó-28), na ocorrência dos eventos de precipitação simulados. Para o evento de 09 de maio de 2016 (121,8mm e $\mathrm{Tr}=2$ anos), observou-se uma vazão máxima afluente ao Nó-28 de $0,42 \mathrm{~m}^{3} / \mathrm{s}$, enquanto para o evento do dia 30 de maio de 2016 (112,8mm e $T r=2$ anos), a vazão máxima afluente ao ponto de controle foi de $0,64 \mathrm{~m}^{3} / \mathrm{s}$.
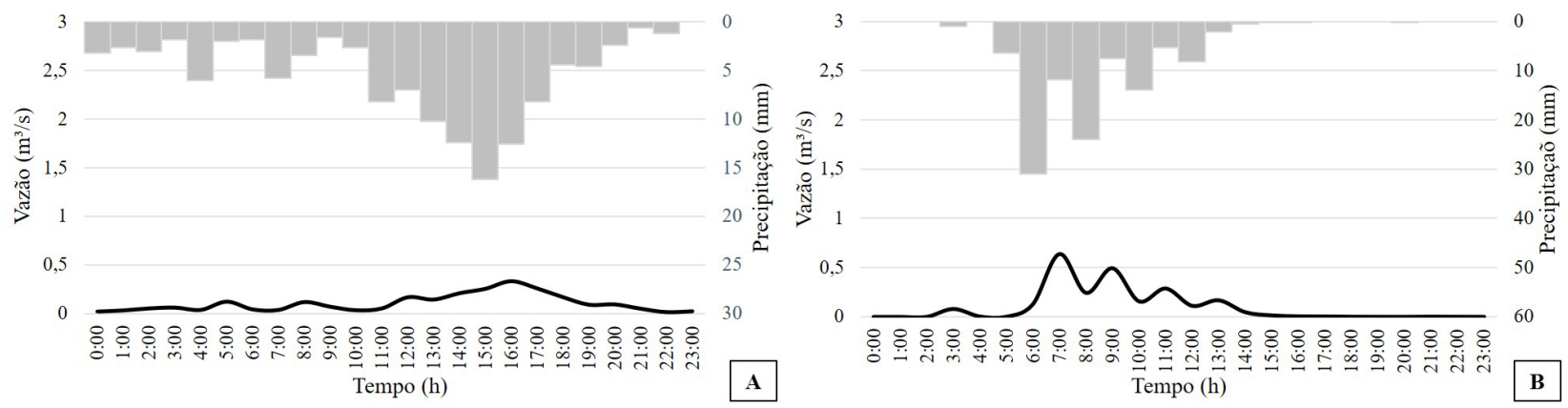

Hietogram Vazão Simulada - Condição Atual

Figura 5 - Hidrograma resultante da calibração do modelo para o evento de 09 de maio de 2016 (a) e 30 de maio de 2016 (b). 
Nos hidrogramas anteriores, é possível observar uma defasagem entre o pico de vazão e a altura máxima de precipitação. No evento do dia 09, por exemplo, a máxima precipitação ocorre às $15 \mathrm{~h} 45$, enquanto o pico de vazão ocorre às $16 \mathrm{~h}$. No outro evento, do dia 30, esse fato também ocorre. A precipitação máxima acontece às $06 \mathrm{~h} 45$ e o pico do hidrograma é registrado às $07 \mathrm{~h}$. Em ambos os casos, tem-se uma defasagem de 15 minutos, caracterizando, assim, o tempo de resposta da bacia à precipitação ocorrida.

Visando validar as vazões simuladas pelo SWMM, com suas hidrógrafas apresentadas na Fig. 5, foi aplicado o Método Racional para a determinação das vazões da área de contribuição ao ponto de controle, considerando um coeficiente de escoamento superficial de 0,85, característico de uma área com urbanização consolidada, conforme estabelece Villela \& Mattos (1975). A Tabela 3 mostra os resultados dos cálculos realizados com base na aplicação do Método Racional considerando os seguintes aspectos:

- Área total de contribuição ao ponto de alagamento, caracterizado pelo Nó-28 = 7,6 hectares.

- Para o evento de 09 de maio de 2016 ( $T r=2$ anos), calculou-se a intensidade da chuva para o período de maior volume precipitado, registrado entre 13 e $16 \mathrm{~h}$ (180 min.).

- O mesmo foi feito para o evento de 30 de maio de 2016 ( $\mathrm{Tr}=2$ anos), cuja intensidade da chuva foi calculada para o período de 2 horas (120 min.), entre 6 e $8 \mathrm{~h}$.

Tabela 3 - Vazões calculadas pelo Método Racional.

\begin{tabular}{|c|c|c|c|c|}
\hline Evento & $\mathbf{t}(\mathbf{m i n})$ & $\mathbf{i}(\mathbf{m m} / \mathbf{h})$ & $\mathbf{P}(\mathbf{D}, \mathbf{T})(\mathbf{m m})$ & $\mathbf{Q}\left(\mathbf{m}^{\mathbf{3}} / \mathbf{s}\right)$ \\
\hline $09 / 05 / 2016$ & 180 & 24,77 & 74,32 & 0,44 \\
\hline $30 / 05 / 2016$ & 120 & 31,65 & 63,31 & 0,57 \\
\hline
\end{tabular}

Para o evento de 09 de maio de 2016, a vazão máxima obtida nas simulações foi de $0,42 \mathrm{~m}^{3} / \mathrm{s}$, enquanto com a aplicação do Método Racional chegou-se a uma vazão de $0,44 \mathrm{~m}^{3} / \mathrm{s}$. No evento de 30 de maio de 2016, a vazão obtida nas simulações foi de $0,64 \mathrm{~m}^{3} / \mathrm{s}$, enquanto pelo Método Racional obteve-se a vazão de $0,57 \mathrm{~m}^{3} / \mathrm{s}$. A partir dessa relação, pode-se concluir que os critérios adotados na calibração do modelo, realizada de forma simplificada, representam bem as condições verificadas em campo na ocorrência dos eventos considerados.

Durante a modelagem, verificou-se que o local apresenta condição desfavorável de escoamento pelos condutos subterrâneos, apresentando trechos de galerias com declividade negativa. Isso mostra que, além da defasagem do sistema de drenagem, concebido para o padrão urbanístico quando implantado, essa irregularidade da rede poderia ser uma das causas dos alagamentos recorrentes na área estudada.

Apesar dessa constatação, a simulação com a readequação das cotas de fundo das galerias mostrou que os aspectos de altura e volume máximos de alagamentos não variaram quando comparados à condição atual, durante os eventos simulados. Essa intervenção garantiu, somente, condições favoráveis para escoamento das águas pluviais através dos condutos, antes dificultado pelas irregularidades presentes da rede. $O$ efeito dessa mudança foi observado nos erros de continuidade gerados nos relatórios de simulação dos eventos, mais especificamente na propagação de vazão entre os condutos.

Mesmo parecendo uma alternativa trivial, um dos grandes problemas na concepção do sistema de drenagem da cidade do Recife são as poucas variações de cotas topográficas superficiais, limitando assim as declividades necessárias para a implantação dos condutos subterrâneos de drenagem, de modo a garantir a eficiência do sistema nos eventos de chuva. Além disso, outro fator importante é a oscilação 
de maré, com grande influência na maior parte dos exutórios dos sistemas de drenagem da cidade, nos períodos em que há coincidência de maré alta e chuva intensa.

Com a persistência na ocorrência de inundações durante os eventos de chuva considerados, a partir do rearranjo da rede de drenagem, foi simulada outra técnica para reduzir os riscos de alagamentos no ponto crítico estudado, descrito a seguir.

\subsection{Simulação do Reservatório de Detenção Implantado em Logradouro}

No dimensionamento do reservatório de detenção, foram considerados dois critérios para a obtenção da vazão de saída (QS), da Eq. 9:

- Aplicando o Método Racional na área de contribuição ao ponto de alagamento (7,6 ha); e

- Utilizando a equação da continuidade num conduto de $0,60 \mathrm{~m}$ de diâmetro, equivalente à galeria principal na sobredita área de contribuição.
No primeiro critério, para definir a intensidade da chuva de projeto, utilizou-se a equação IDF do Recife, adotou-se o tempo de recorrência de 2 anos (coincidente com o período de retorno dos eventos de precipitação simulados) com a duração da chuva igual ao tempo de concentração médio da área de montante ao ponto crítico estudado (15 min). O coeficiente de escoamento adotado (C) foi de 0,85 (valor médio), característico de área com urbanização consolidada (Wilken, 1978).

No segundo critério, em que a vazão de saída (Qs) da área de contribuição ao ponto de alagamento é equivalente à vazão máxima da galeria situada na referida área, fazendo uso da equação da continuidade, considerou-se a seção plena (preenchida) da galeria de $\emptyset=0,60 \mathrm{~m}$, adotando a velocidade máxima admissível para condutos de concreto de $4,5 \mathrm{~m} / \mathrm{s}$ segundo o DNIT - Departamento Nacional de Infraestrutura de Transportes (DNIT, 2006).

A Tabela 4 apresenta os resultados do dimensionamento proposto, considerando os critérios mencionados anteriormente.

Tabela 4 - Aplicação do método das chuvas segundo Baptista et al. (2011).

\begin{tabular}{|c|c|c|c|c|c|c|c|}
\hline Critério & $\begin{array}{c}\text { TR } \\
\text { (anos) }\end{array}$ & i (mm/h) & $P(D, T)(m m)$ & $\mathrm{Q}_{\mathrm{s}}\left(\mathrm{m}^{3} / \mathrm{s}\right)$ & $\begin{array}{l}q_{s}=Q_{s} / A_{q} \\
(\mathrm{~mm} / \mathrm{min})\end{array}$ & $\begin{array}{l}\text { Altura a armaz. } \\
\qquad \mathrm{P}-q_{s} t(\mathrm{~mm})\end{array}$ & $\begin{array}{c}\text { Volume a } \\
\text { armaz. }\left(\mathrm{m}^{3}\right)\end{array}$ \\
\hline 1 & \multirow{2}{*}{2} & \multirow{2}{*}{95,63} & \multirow{2}{*}{23,91} & 1,72 & 1,59 & 12,11 & 782,31 \\
\hline 2 & & & & 1,26 & 1,17 & 15,22 & 983,21 \\
\hline
\end{tabular}

Além dos métodos aplicados para a obtenção do volume de reservação, é fundamental compatibilizar as dimensões necessárias para o armazenamento com as condições locais, tendo como base a largura dos logradouros e profundidade dos poços de visita existentes.

Devido às limitações de espaço (pequenas variações de cota), obteve-se um volume disponível para armazenamento de $740 \mathrm{~m}^{3}$, valor este bas- tante próximo dos volumes obtidos pelo método das chuvas para a recorrência de 2 anos. A partir deste volume, obteve-se o dimensionamento do reservatório de detenção (Fig. 6), cujas paredes e lajes têm espessura de $0,25 \mathrm{~m}$, área interna de $740 \mathrm{~m}^{2}$ e altura útil interna de $1,00 \mathrm{~m}$. O reservatório foi locado na área alagada, em volta do Nó28 (ponto de controle), com a rede de drenagem de entrada e saída ao reservatório com diâmetro de $\varnothing=0,60 \mathrm{~m}$. 


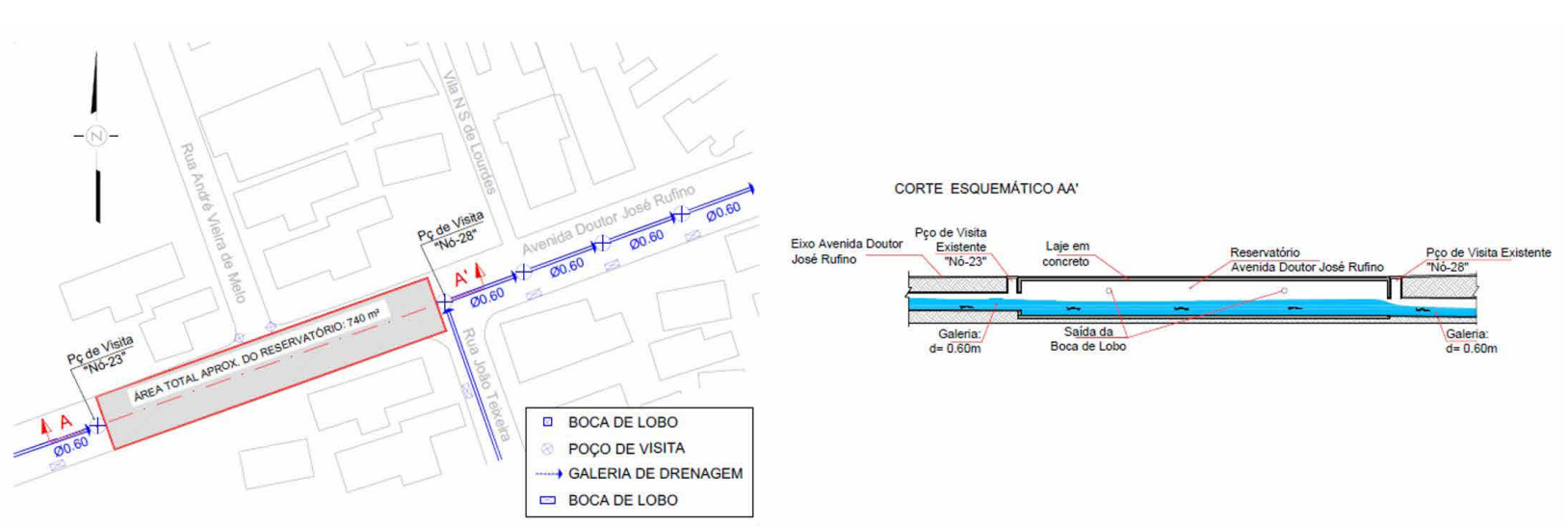

Figura 6 - Reservatório de detenção on-line na rede de drenagem da Avenida Doutor José Rufino.

A Fig. 7 mostra as hidrógrafas simuladas na rede de drenagem, à jusante do poço de visita Nó 28, para os cenários sem e com controle de vazão (reservatório) durante os eventos de 09 e 30 de maio de 2016. Na análise das vazões simuladas, constata-se uma redução média nos valores de pico de $63,85 \%$ para ambos os eventos consi-

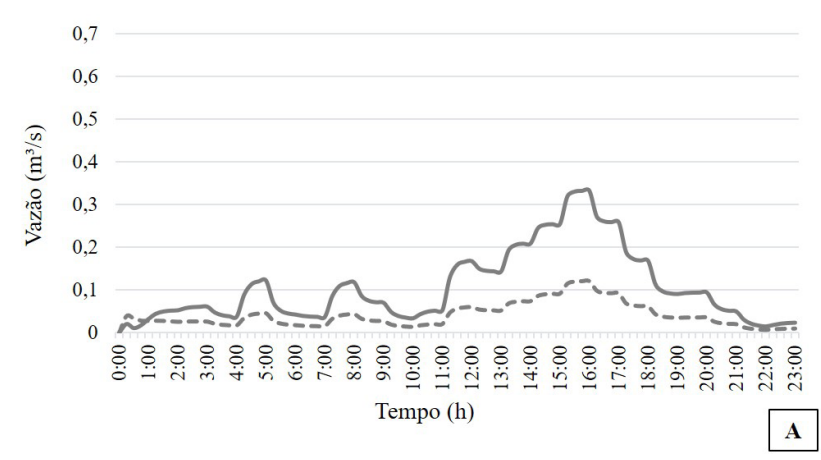

derados. Também é possível notar que, com a implantação do reservatório na rede, o mesmo passa a amortecer as vazões após $4 \mathrm{~h}$ de precipitação, quando já havia chovido 16,6mm (para o evento do dia 09). Já no evento do dia 30 , as vazões passam a ser amortecidas quando se havia precipitado $7,4 \mathrm{~mm}$ em $5 \mathrm{~h}$.

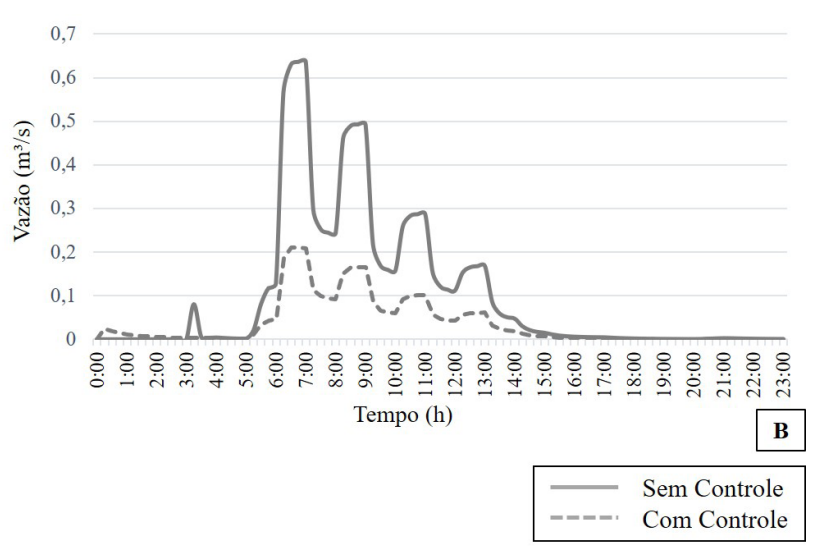

Figura 7 - Hidrogramas a jusante do Nó-28 (sem e com controle de vazão) para o evento de 09 de maio de 2016 (a) e 30 de maio de 2016 (b).

A Fig. 8 mostra as vazões de entrada (afluente ao Nó-23) e de saída do reservatório (efluente do Nó-28), evidenciando a redução das vazões de pico afluentes ao mesmo. Analisando a relação entre a vazão afluente e efluente verificase que, para o evento de 09 de maio de 2016, $43,7 \%$ do volume afluente ao reservatório é armazenado. Para o evento de 30 de maio de
2016, observa-se que $46,4 \%$ do volume afluente ao reservatório é armazenado. Pode-se concluir que o reservatório possui uma capacidade percentual de acumulação de $45 \%$ da vazão montante ao ponto crítico de alagamento. Portanto, o tamanho do reservatório é adequado para amortizar o total precipitado em eventos com recorrência de 2 anos. 

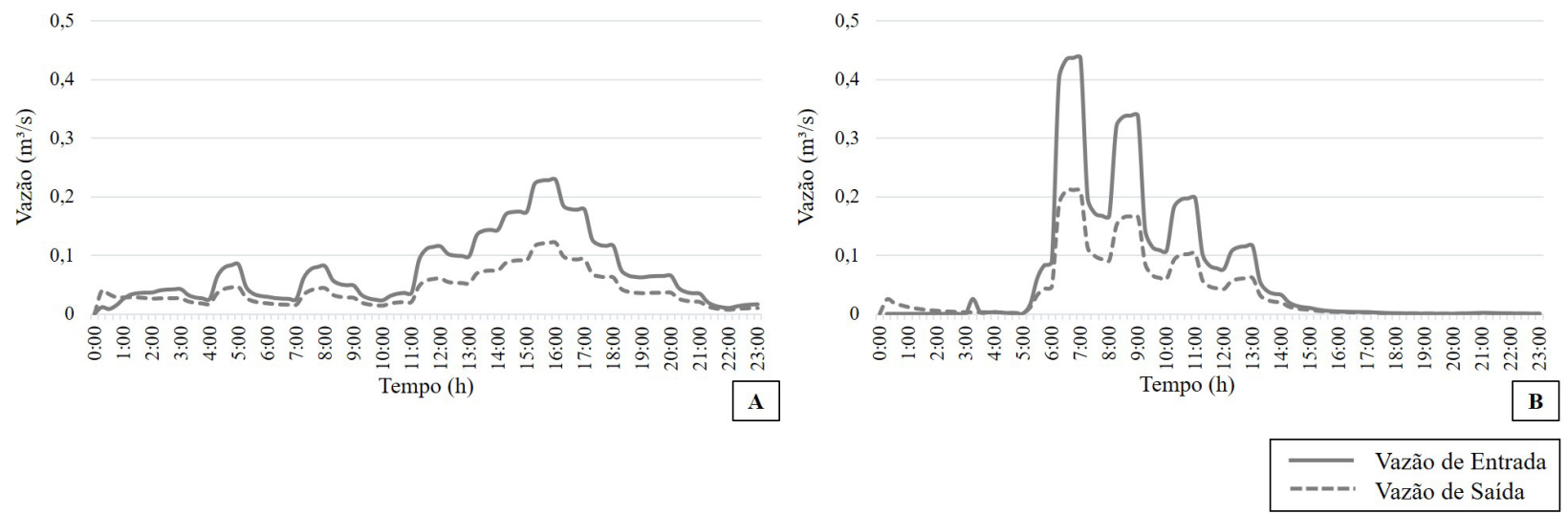

Figura 8 - Hidrogramas de entrada e saída do reservatório para o evento de 09 de maio de 2016 (a) e 30 de maio de 2016 (b).

\subsection{Orçamento Estimativo Associado à Construção do Reservatório}

A Tabela 5 mostra o orçamento referente à construção do reservatório proposto, baseado em tabelas de precificação dos serviços da EMLURB (EMLURB, 2018), disponibilizadas em site da instituição. Também foram agregados ao custo do reservatório a substituição de toda a rede de galeria principal situada a jusante do mesmo, até o exutório no rio Jiquiá. Esse custo adicional é necessário e complementa a solução proposta, onde deverão ser reajustadas as declividades das galerias, garantindo, assim, o escoamento por gravidade, sem interferências.

Tabela 5 - Custo estimado para a construção do reservatório (Data base: julho/2018).

\begin{tabular}{|c|c|c|c|c|}
\hline Código & Descrição & Unid. & Quant.* & Preço (R\$) \\
\hline \multicolumn{4}{|c|}{ 1. SERVIÇOS PRELIMINARES } & $58.593,85$ \\
\hline 02.01 .200 & $\begin{array}{l}\text { Serviço topográfico de pequeno porte, diária de uma equipe com topógrafo, quatro } \\
\text { auxiliares, teodolito, nível ótico, etc. }\end{array}$ & un & 5,00 & $6.801,35$ \\
\hline 03.01 .222 & Demolição de pavimentação asfáltica com martelete pneumático. & $\mathrm{m}^{2}$ & $1.265,00$ & $19.101,50$ \\
\hline 03.03 .045 & $\begin{array}{l}\text { Fornecimento e montagem de tela de sinalização laranja }(h=1,2 \mathrm{~m}) \text {, fixada em montantes de } \\
\text { ferro de } 1 / 2 \text { pol. ou em barrotes de madeira } 3 \times 3 \text { pol. colocados sobre base de concreto traço } \\
1: 4: 8 \text {, espaçados a cada } 2 \mathrm{~m} \text {, inclusive posterior retirada e reaproveitamento. }\end{array}$ & $\mathrm{m}$ & $1.500,00$ & $18.435,00$ \\
\hline 04.02 .040 & Transporte de material com D.M.T. $6 \mathrm{~km}$. & $\mathrm{m}^{3}$ & $1.440,00$ & $14.256,00$ \\
\hline \multicolumn{4}{|c|}{ 2. ESTRUTURA DE DRENAGEM (EM CONCRETO) } & $698.323,01$ \\
\hline 05.01 .180 & $\begin{array}{l}\text { Escavação e carga mecânicas de material de } 1^{\mathrm{a}} \text { categoria, proveniente de corte de subleito, } \\
\text { e ainda transporte com D.M.T. } 6 \mathrm{~km} \text {. }\end{array}$ & $\mathrm{m}^{3}$ & $1.174,80$ & $19.830,63$ \\
\hline 06.01 .055 & $\begin{array}{l}\text { Fôrmas para concreto armado em qualquer tipo de estrutura, com chapa de madeira } \\
\text { compensada tipo resinada de } 12 \mathrm{~mm} \text {, inclusive escoramento. }\end{array}$ & $\mathrm{m}^{2}$ & $1.173,55$ & $120.863,91$ \\
\hline 06.02 .020 & Ferro cortado, dobrado e colocado na fôrma, em infraestrutura (CA-50). & $\mathrm{kg}$ & $34.400,00$ & $286.552,00$ \\
\hline 06.03 .010 & Concreto não estrutural para lastros de pisos e fundações, lançado e adensado. & $\mathrm{m}^{3}$ & 78,23 & $32.650,07$ \\
\hline 06.03 .092 & Concreto estrutural com fck $25 \mathrm{MPa}$, lançado em estruturas e adensado. & $\mathrm{m}^{3}$ & 430,00 & $238.426,40$ \\
\hline \multicolumn{4}{|c|}{ 3. GALERIAS DE DRENAGEM } & $76.353,00$ \\
\hline 21.06 .401 & $\begin{array}{l}\text { Tubos de concreto PA1-0,60m, inclusive escavação mecânica das valas até } 1,50 \text { m de } \\
\text { profundidade, reaterro compactado, remoção do material excedente e ainda fornecimento } \\
\text { e assentamento dos tubos. }\end{array}$ & $\mathrm{m}$ & 300,00 & $76.353,00$ \\
\hline
\end{tabular}

continua... 
Tabela 5 - Continuação...

\begin{tabular}{|c|c|c|c|c|}
\hline \multicolumn{4}{|c|}{ 4. PAVIMENTAÇÃO } & $\begin{array}{l}\text { Preço (R\$) } \\
82.931,76\end{array}$ \\
\hline 20.01.010 & $\begin{array}{l}\text { Regularização do subleito, abrangendo escarificação, homogeneização, umedecimento } \\
\text { e compactação com espessura de } 15 \mathrm{~cm} \text {, teor de compactação a } 100 \% \text { AASHO normal } \\
\text { (DNER-ME 47-64). }\end{array}$ & $\mathrm{m}^{2}$ & $1.440,00$ & $2.390,40$ \\
\hline 20.02.010 & $\begin{array}{l}\text { Exec. de sub-base estabilizada granulometr. abrangendo espalhamento, homog., } \\
\text { umedecimento e compactação com espessura de } 12 \mathrm{~cm} \text {, teor de compactação a } 100 \text { por } \\
\text { cento AASHO intermed. (DNER-ME 48-64), inclusive fornec. do material prov. de jazida (CBR } \\
\text { 20\%), D.M.T. } 12 \mathrm{~km} \text {. }\end{array}$ & $\mathrm{m}^{2}$ & $1,440,00$ & $15.408,00$ \\
\hline 20.03.200 & $\begin{array}{l}\text { Execução de base com brita graduada abrangendo espalhamento e compactação da } \\
\text { mistura em camadas sucessivas com } 15 \mathrm{~cm} \text { de espessura, inclusive fornecimento do } \\
\text { material. }\end{array}$ & $\mathrm{m}^{3}$ & 216,00 & $21.604,32$ \\
\hline 20.04 .014 & Imprimação mecânica com $30 \mathrm{~cm}$, taxa $1,21 / \mathrm{m}^{2}$. & $\mathrm{m}^{2}$ & $1.440,00$ & $1.814,40$ \\
\hline 20.04.044 & Pintura asfáltica com aplicação manual, emulsão catiônica RR-1C, taxa de 0,5l/m². & $\mathrm{m}^{2}$ & $1.440,00$ & $5.083,20$ \\
\hline 20.05.122 & $\begin{array}{l}\text { Concreto betuminoso usinado a quente, para camada de rolamento, } 6 \% \text { de cap. em média, } \\
\text { inclusive aplicação e compactação. }\end{array}$ & $\mathrm{m}^{3}$ & 72,00 & $36.631,44$ \\
\hline \multicolumn{4}{|c|}{ PREÇO TOTAL (RS) } & $916.201,62$ \\
\hline
\end{tabular}

"Os quantitativos foram levantados do projeto básico elaborado para o reservatório, considerando o volume dimensionado $\left(740 \mathrm{~m}^{3}\right)$. 0 desenho esquemático do reservatório pode ser observado na Fig. 6.

De maneira geral, tem-se observado que tal investimento recai sobre o poder público municipal, não só para a construção, mas também, para a manutenção sistêmica da solução adotada. A manutenção do reservatório de detenção no bairro do Espinheiro, por exemplo, é feita, em média, anualmente pela EMLURB, geralmente antes do período chuvoso. O custo dessa manutenção baseia-se no volume de resíduos retirados do reservatório e na mão de obra utilizada. É importante ressaltar que a sobredita manutenção deve ser feita não só na estrutura de controle, mas também, em toda a rede de drenagem integrante ao reservatório, principalmente a jusante do mesmo.

\section{CONCLUSÕES}

Ao longo dos séculos, a ocupação do solo urbano no Recife vem causando aterramento das áreas de mananciais para abrir espaço para a construção de vias públicas e de moradias quase sempre irregulares. No bairro do Jiquiá, apesar de a Lei Municipal No 16.176 de Uso e Ocupação do Solo (Recife, 1996) requisitar que $25 \%$ da área do lote se man- tenha com solo natural, observou-se um alto grau de impermeabilização, com taxa acima de $90 \%$, dificultando consideravelmente a capacidade de infiltração da água da chuva. Aliado a esse fato, tem-se a ineficiência do sistema de drenagem da área estudada, que foi concebido para um padrão urbanístico diferente do existente atualmente.

Com essa realidade comum aos grandes centros urbanos brasileiros, torna-se difícil encontrar espaço em meio às metrópoles para a locação de bacias de detenção ou realização de desconexão entre as áreas impermeáveis e a rede de drenagem para redirecionamento do escoamento até as áreas verdes, como é previsto pelas técnicas sustentáveis. Por esse motivo, optou-se pelo reservatório de detenção enterrado, sob o sistema viário, como uma solução. É válido destacar que tal solução é uma forma de compensar os efeitos danosos do processo de urbanização, enquadrando-a como alternativa compensatória e/ou corretiva. Desse modo, a torna uma estrutura definitiva e integrante da rede de drenagem local, necessitando, apenas, de manutenção para sua adequada funcionalidade. 
Outro ponto importante é que tal solução pode ser adotada em outras áreas de urbanização consolidada, atentando para as características da drenagem local, a disponibilidade de área para locação do reservatório e condição de escoamento (saída do reservatório) por gravidade.

Tecnicamente, observou-se que a implantação da sobredita solução, com capacidade de armazenamento de $740 \mathrm{~m}^{3}$, é satisfatória para os eventos de precipitação com recorrência de 2 anos. No entanto, para eventos de chuva com recorrências superiores, é provável que os alagamentos tornem a ocorrer, porém em proporções menores e com tempos de inundação reduzidos. Para os eventos simulados, os resultados mostraram que o volume de alagamento foi reduzido, em média, $45 \%$. Houve, também, a amortização dos picos de vazão em $63,85 \%$, o que melhorou as condições de escoamento na rede de jusante ao reservatório.

Apesar de se mostrar uma solução viável, o custo de implantação é elevado e necessita de manutenção sistêmica não só da estrutura de controle, mas também de toda a rede de drenagem integrante ao reservatório. Além disso, na hipótese de construção do reservatório sob a via, outros aspectos precisam ser avaliados, tendo em vista o impacto da obra no comércio local e na mobilidade de veículos e pedestres. Apesar dessa condição temporária, os prejuízos financeiros para os moradores e comerciantes locais, bem como os transtornos para mobilidade urbana na área, seriam reduzidos em dias de chuva.

Em suma, os pontos elencados mostram a importância de uma abordagem integrada do planejamento urbano com a gestão das águas pluviais urbanas, buscando minimizar os impactos do alto grau de impermeabilização do solo por meio de soluções compensatórias que incluam técnicas alternativas de drenagem. Adicionalmente, ações de prevenção aos riscos de alagamentos também são necessárias, como a manutenção da infraestrutura de drenagem e a conscientização da população, além do disciplinamento e do ordenamento do uso e ocupação do solo, que são atribuições da prefeitura e deverão estar na agenda política do município.

\section{AGRADECIMENTOS}

Os autores agradecem à EMLURB (Empresa de Manutenção e Limpeza Urbana) pelo fornecimento de informações cadastrais da rede de drenagem urbana, à Facepe (Fundação de Amparo à Ciência e Tecnologia do Estado de Pernambuco) pela concessão de bolsa de doutorado para o segundo autor e à Capes (Coordenação de Aperfeiçoamento de Pessoal de Nível Superior) pela concessão de bolsa de mestrado para o terceiro autor.

\section{CONTRIBUIÇÃO DOS AUTORES}

Todos os autores contribuíram de forma igualitária.

\section{REFERÊNCIAS}

BAPTISTA, M.; NASCIMENTO, N.; BARRAUD, S. (Coordenadores). Técnicas compensatórias em drenagem urbana - $2^{\mathbf{a}}$ edição. Porto Alegre: Associação Brasileira de Recursos Hídricos, 318 p., 2011.

CABRAL, J.J.S.P.; MASCARENHAS, F.B.; CASTRO, M.A.H.; MIGUEZ, M.G.; PEPLAU, G.R.; BEZERRA, A.A. Modelos Computacionais para Drenagem Urbana. In: RIGHETTO, A.M. (Coordenador), Manejo de águas pluviais urbanas. Natal: PROSAB-ABES, p. 112-148, 2009.

CANHOLI, A.P. (Coordenador). Drenagem urbana e controle de enchentes - 2a edição. São Paulo: Oficina de Textos, 384 p., 2015.

CTTU - AUTARQQUIA DE TRÂNSITO E TRANSPORTE URBANO DO RECIFE. Imagens da câmera de monitoramento da Avenida Doutor José Rufino em 09 e 30 de maio de 2016. Disponível em: http://transito.gtrans.com.br/cttupe/index.php/mapa. Acessado em: 10jun2016.

DHN - DIRETORIA DE HIDROGRAFIA E NAVEGAÇÃO. Tábua de Maré do Porto do Recife (2016). Disponível em: https://www. marinha.mil.br/chm/dados-do-segnav/dados-de-mare-mapa?field_tipo_de_dados_value=T\%C3\%81BUAS+DE+MAR\%C3\%89 Acessado em: 01 ago2016. 
DNIT - DEPARTAMENTO NACIONAL DE INFRAESTRUTURA DE TRANSPORTES. Manual de drenagem de rodovias - $\mathbf{2}^{\mathbf{a}}$ edição. Rio de Janeiro: Diretoria de Planejamento e Pesquisa / Coordenação Geral de Estudos e Pesquisa, 327 p., 2006.

ELETROBRÁS/PROCEL-SANEAR. EPA SWMM 5.0 - Modelo de gestão de drenagem urbana (manual do usuário). João Pessoa: LENHS-UFPB, 280 p., 2012.

EMLURB - EMPRESA DE MANUTENÇÃO E LIMPEZA URBANA. Plano Diretor de Drenagem e Manejo das Águas Urbanas do Recife. (Versão concedida em visita técnica). Recife: Prefeitura da Cidade do Recife (PCR), 2016.

. Tabela de preços da EMLURB (data base: julho/2018) Disponível em: https://www.recife.pe.gov.br/pr/servicospublicos/ emlurb/eosei/tabela.php Acessado em: 01jun2019.

FORMIGA, K.T.M.; CARVALHO, M.; SILVA, K.A.; SOARES, A.K. Calibração do Storm Water Management Model (SWMM) utilizando algoritmos evolucionários multiobjetivo. Engenharia Sanitária e Ambiental, v. 21, n. 4, p. 697-707, 2016. https://doi.org/10.1590/ s1413-41522016131862

IBGE - INSTITUTO BRASILEIRO DE GEOGRAFIA E ESTATÍSTICA Censo Demográfico de 2000. Disponível em: http://www.ibge. gov.br. Acessado em: 09abr2015.

IBGE - INSTITUTO BRASILEIRO DE GEOGRAFIA E ESTATÍSTICA. Censo Demográfico de 2010. Disponível em: http://www.ibge. gov.br. Acessado em: 09abr2015.

LIONG, S.Y. \& IBRAHIM, Y. Estimation of peak flow and runoff volume with response surface method. Journal of Water Resources Planning Management, v. 120, n. 2, p. 161-175, 1994.

MELO, T.A.T.; COUTINHO, A.P.; CABRAL, J.J.S.P.; CIRILO, J.A.; ANTONINO, A.C.D. Desafios para o manejo das águas pluviais na cidade do Recife - A contribuição da UFPE. In: XX SIMPÓSIO BRASILEIRO DE RECURSOS HÍDRICOS, 2013, Bento Gonçalves. Anais... Bento Gonçalves: ABRH, 2013, p. 1-8.

NEVES, M.G.F.P.; TASSI, R.; ALLASIA, D.G.; VILLANUEVA, A.O.N. Propostas de melhorias nos reservatórios para controle de cheias urbanas. In: XX CONGRESO NACIONAL DEL AGUA Y III SIMPOSIO DE RECURSOS HIDRICOS DEL CONO SUR, 2005, Mendoza. Anais... Mendoza: CONAGUA, 2005, p. 1-12.

OLIVEIRA, R.L.M. Alternativas compensatórias para drenagem urbana em ponto crítico da cidade de Recife - PE. Recife, 2017.
101 p. Dissertação (Mestrado em Engenharia Civil) - Escola Politécnica de Pernambuco, Universidade de Pernambuco.

RECIFE. Lei no 16.176, de 09 de abril de 1996: Estabelece a Lei de Uso e Ocupação do Solo da Cidade do Recife. Disponível em: http://www.legiscidade.recife.pe.gov.br/lei/16176/. Acessado em: 15 jan2018.

SILVA, P.O. \& CABRAL, J.J.S.P. Atenuação de picos de vazão em área problema: estudo comparativo de reservatórios de detenção em lote, em logradouros e em grande área da bacia. Revista Brasileira de Recursos Hídricos, v. 19, n. 2, p. 7-18, 2014. https://doi. org/10.21168/rbrh.v19n2.p7-18

SILVA JUNIOR, M.A.B. Alternativas compensatórias para controle de alagamentos em localidade do Recife-PE. Recife, 2015. 154 p. Dissertação (Mestrado em Engenharia Civil) - Escola Politécnica de Pernambuco, Universidade de Pernambuco.

SILVA JUNIOR, M.A.B. \& SILVA, S.R. Impacts of urbanization and climate change in the drainage system of Recife/PE. Revista Brasileira de Geografia Física, v. 9, n. 6, p. 2034-2053, 2016. https:// doi.org/10.26848/rbgf.v9.6.p2034-2053

SILVA JUNIOR, M.A.B.; SILVA, S.R.; CABRAL, J.J.S.P. Compensatory alternatives for flooding control in urban areas with tidal influence in Recife - PE. Revista Brasileira de Recursos Hídricos, v. 22, e19, p. 1-12, 2017a. http://dx.doi.org/10.1590/23180331.011716040

SILVA JUNIOR, M.A.B.; OLIVEIRA, R.L.M.; CABRAL, J.J.S.P.; SILVA, P.O.; SILVA, S.R. Reservatório de detenção em logradouros como alternativa para os alagamentos urbanos: uma análise para a cidade do Recife-PE. In: XXII Simpósio Brasileiro de Recursos Hídricos, 2017b, Florianópolis. Anais... Florianópolis: ABRH, 2017b, p. 1-8.

TUCCI, C.E.M. Coeficiente de escoamento e vazão máxima das bacias urbanas. Revista Brasileira de Recursos Hídricos, v. 5, n. 1, p. 61-68, 2000. http://dx.doi.org/10.1590/2318-0331.011716040

TUCCI, C.E.M. (Coordenador). Hidrologia: ciência e aplicação. $4^{\mathrm{a}}$ ed. $7^{\mathrm{a}}$ reimpressão, Porto Alegre: UFRGS/ABRH, 2015.

VILLELA, S.M. \& MATTOS, A. (Coordenadores). Hidrologia Aplicada. São Paulo: Ed. McGraw Hill do Brasil, 245 p., 1975.

WILKEN, P.S. Engenharia de drenagem superficial. 1 ed. São Paulo: CETESB, 1978. 